\title{
Retesting the childhood-onset GH-deficient patient
}

\author{
V Gasco, G Corneli ${ }^{1}$, G Beccuti, F Prodam ${ }^{1}$, S Rovere, J Bellone, S Grottoli, G Aimaretti ${ }^{1}$ and E Ghigo \\ Division of Endocrinology and Metabolism, Department of Internal Medicine, University of Turin, Turin, Italy and ${ }^{1}$ Endocrinology Unit, Amedeo Avogadro \\ University of Novara, Novara, Italy \\ (Correspondence should be addressed to E Ghigo who is now at Divisione di Endocrinologia e Metabolismo, Ospedale SGB Molinette, C.so Dogliotti 14, \\ 10126 Torino, Italy; Email: ezio.ghigo@unito.it)
}

\begin{abstract}
GH deficiency (GHD) in adults has to be shown by a single provocative test, provided that it is validated. Insulin tolerance test (ITT) has been indicated as the test of choice; now also glucagon test is validated and represents an alternative. The GHRH plus arginine (ARG) test and testing with GHRH plus a GH secretagogue are equally reliable diagnostic tools, and are now considered as 'golden' standards as ITT. Childhood-onset (CO) GHD needs retesting in late adolescence or young adulthood; this is a major clinical challenge and raises questions about the most appropriate method and cut-off value. Appropriate re-evaluation of GH status is represented by simple measurement of IGF1 concentration off rhGH treatment. Clearly, low IGF1 levels are evidence of persistent severe GHD in subjects with genetic GHD or panhypopituitarism. However, normal IGF1 levels never rule out severe GHD and CO-GHD with normal IGF1 levels must undergo a provocative test. The appropriate GH cut-off limit is specific for each provocative test. As shown by the ROC curve analysis, in late adolescents and young adults, the lowest normal GH peak response to ITT is $6.1 \mu \mathrm{g} / \mathrm{l}$ while that to GHRH + ARG test is $19.0 \mu \mathrm{g} / \mathrm{l}$. These cut-off limits, however, are just indicative as being variable as a function of the assay used. No other test is validated for retesting. As GHRH + ARG test mostly explores the GH-releasable pool, normal GH response would be verified by a second ITT in order to rule out subtle hypothalamic defect.
\end{abstract}

European Journal of Endocrinology 159 S45-S52

\section{Introduction}

Adults with GH deficiency (GHD) have impaired health, which improves with GH replacement. GHD in adults leads to impairment in body composition and function, as well as to deranged lipoprotein and carbohydrate metabolism and increased cardiovascular morbidity (1-4). This impairment has been shown to be even more severe when GHD is childhood-onset (CO) either congenital or acquired (5-8). Based on the evidence that GHD in adults is a new syndrome which may benefit from $\mathrm{GH}$ replacement, health authorities in many countries have approved the therapeutic use of GH in hypopituitaric patients with severe GHD (1-3).

\section{Diagnosis of adult GHD: who and how to test Who to test}

Severe GHD is defined biochemically within an appropriate clinical context.

This paper was presented at the 5th Ferring International Paediatric Endocrinology Symposium, Baveno, Italy (2008). Ferring Pharmaceuticals has supported the publication of these proceedings.
The present recommendations state that patients who should be tested for GHD are those who show evidence of hypothalamic-pituitary disease, and in whom there is an intention to treat $(2,4)$. This includes patients from the following groups:

(i) those with signs and symptoms of hypothalamic-pituitary disease (endocrine, structural and/or genetic causes),

(ii) those who have received cranial irradiation or tumour treatment,

(iii) those with CO-GHD and

(iv) those with traumatic brain injury (TBI) or subarachnoid haemorrhage.

In fact, TBI as well as subarachnoid haemorrhage is now appreciated as cause of hypopituitarism. The severity of TBI is not well correlated with the degree of pituitary dysfunction. As the GH axis may recover after TBI, testing for GHD should be undertaken no sooner than 12 months after the injury $(2,4)$.

\section{How to test}

The GH Research Society (GRS) Consensus of 1997 stated that the diagnosis of adult GHD is established 
by provocative testing of $\mathrm{GH}$ secretion and recommended the insulin tolerance test (ITT) to be the diagnostic test of choice with the combined administration of arginine (ARG) and GHRH as the most promising alternative. Administration of ARG alone or with glucagon could be considered, but with less established diagnostic value (1).

The strong recommendation about the diagnosis is done by provocative tests only, based on the evidence that a normal serum IGF1 does not exclude the diagnosis of GHD in adults. A serum IGF1 below the normal range was considered just suggestive of GHD (in the absence of other conditions known to lower IGF1 levels such as malnutrition, hepatic disease, poorly controlled diabetes mellitus and hypothyroidism) even if it was recognized that, in the presence of multiple pituitary deficits, low IGF1 levels were strongly predictive of severe GHD.

In more recent years, some definite diagnostic value of measuring IGF1 has been considered. In fact, total IGF1 is a parameter with good intra-individual reproducibility and positively associated with the peak $\mathrm{GH}$ response to provocative tests (9).

By analyzing the clinical characteristics and biochemical testing results of over 800 patients with either adult-onset hypothalamic or pituitary disease or CO-GHD, it has been demonstrated that adult GHD can be predicted with $95 \%$ accuracy by the presence of either three or four pituitary hormone deficits or a low IGF1 level (10). These findings have been confirmed by others who also proposed an IGF1 cut-off limit of around -2 s.D. All agree that the diagnostic reliability of low IGF1 levels is satisfactory when patients with CO severe GHD or multiple pituitary deficits are considered, particularly below 40 years of age $(2,4,11-15)$. These patients therefore do not require a $\mathrm{GH}$ stimulation test to make the diagnosis of adult GHD; however, it remains that patients suspected for GHD showing normal IGF1 levels must undergo provocative tests $(2,4)$.

Among the provocative tests, the recent 2007 GRS Consensus recognized that GHRH+ARG, GHRH+GH secretagogue (GHS) and glucagon stimulation tests are also now well validated in adults and should be considered golden standard tests as ITT $(2,4)$.

Among classical provocative tests, while the diagnostic reliability of ITT has been confirmed by many studies, the glucagon test has been validated more recently showing quite good sensitivity (Se) and specificity (Sp) $(16,17)$. On the other hand, it has been demonstrated that testing with ARG alone should not be considered a reliable alternative test (18). ITT and glucagon are therefore the only classical provocative tests that are reliable for the diagnosis of adult GHD, although the cut-off levels of the GH response to these tests have, however, never been validated by body mass index (BMI) (4).

The normal limits as well as the within-subject reproducibility of the $\mathrm{GH}$ response to either GHRH+ ARG or GHRH + GHS (namely GHRP-6) have been very well defined in a large cohort of normal subjects $(2,4)$. No significant gender- or age-related differences were found. The mean peak GH response to these 'maximal' tests is clearly higher than that to the majority of other classical provocative tests. Also, it has been demonstrated that these tests distinguish adult GHD patients from normal subjects and that they are at least as sensitive as ITT, provided that appropriate cut-off limits are considered. In fact, there is strict positive association between the peak $\mathrm{GH}$ response to these tests and that recorded after ITT in hypopituitaric patients with $\operatorname{GHD}(4,19)$.

It has been emphasized that the ITT evaluates the integrity of the hypothalamic-pituitary axis and has the added advantage of also stimulating adrenocorticotropin (ACTH) levels, while the combined tests evaluate just the maximal secretory capacity of somatotroph cells. However, it is recognized that each test has limitations. The ITT can be contraindicated in patients with ischaemic heart disease or seizures and in the elderly. Moreover, the response to ITT suffers more marked intraindividual variability. However, since the combined tests stimulate both the hypothalamus and the pituitary, GHD due to hypothalamic disease may be missed $(2,4)$. This is exemplified by studies in those patients treated with cranial irradiation in which the ITT shows the greatest Se and Sp within the first 5 years after irradiation $(2,4$, 20). If the peak GH level during a GHRH + ARG test is normal in those who have received irradiation, then an ITT should also be performed. In irradiated patients as well as those with inflammatory and infiltrative lesions, GHD may develop many years after the initial insult. Therefore, this group should be followed long term with repeat testing as clinically indicated.

Generally, one stimulation test is sufficient for the diagnosis of adult GHD. Not all patients suspected of having GHD, however, require a $\mathrm{GH}$ stimulation test for diagnosis. As anticipated, patients with three or more pituitary hormone deficiencies and an IGF1 level below the reference range have a greater than $97 \%$ chance of being GHD, and therefore do not need a GH stimulation test $(2,4)$.

Regarding the cut-off level appropriate for each provocative test, particular attention focused on the confounding effect of overweight and obesity on the interpretation of the GH response to stimuli. In fact, it is clearly demonstrated that both spontaneous and stimulated GH secretion is negatively associated with $\mathrm{BMI}$ and the $\mathrm{GH}$ response in obese subjects is sometimes as impaired as that in hypopituitary patients with severe GHD (4). The impairment of GH secretion as a function of overweight and obesity would reflect alterations in the neuroendocrine control of the somatotropic axis and/or metabolic alterations (21).

Given the confounding effect of overweight or obesity on the interpretation of the GH response to provocative tests, cut-off levels of $\mathrm{GH}$ response should be appropriate to lean, overweight and obese subjects in order to avoid false-positive diagnosis in obese adults, but also falsenegative diagnosis in lean GHD adults. 
Therefore, the cut-offs for the diagnosis of GHD vary with the test used and also as a function of BMI. For the ITT, the validated cut-off for GHD in adults is a peak GH response of $<3 \mu \mathrm{g} / \mathrm{l}$; the same applies to glucagon test but both tests have not been validated in obesity $(1,2,4)$. The following cut-off levels have been validated for GHRH+ ARG: for those with a BMI $<25 \mathrm{~kg} / \mathrm{m}^{2}$, a peak $\mathrm{GH}<$ $11 \mu \mathrm{g} / \mathrm{l}$; for BMI $25-30 \mathrm{~kg} / \mathrm{m}^{2}$, a peak $\mathrm{GH}<8 \mu \mathrm{g} / \mathrm{l}$; for $\mathrm{BMI}>30 \mathrm{~kg} / \mathrm{m}^{2}$, a peak $\mathrm{GH}<4 \mu \mathrm{g} / \mathrm{l}(22)$. On the other hand, the cut-off level validated for the GHRH+GHRP-6 below which severe GHD is demonstrated is $10.0 \mu \mathrm{g} / \mathrm{l}$ in lean subjects but $5.0 \mu \mathrm{g} / \mathrm{l}$ in obese patients $(23,24)$.

These cut-off limits, however, are only indicative, since they are variable as a function of the assay used. The analytic method influences the results of $\mathrm{GH}$ stimulation test and ideally assay-specific cut-off values should be defined for each stimulation test. Substantial heterogeneity exists among presently utilized assays, which would be reduced by the adoption of a universal GH calibration standard. The GRS in its last guidelines for the diagnosis and treatment of GHD advocates the use of recombinant $22 \mathrm{kDa} \mathrm{GH}$ calibrator (2). Similar problems exist for IGF1 measurement. A universal calibrator is essential and should be recombinant human IGF1 of the highest purity. This should be adopted by all assay manufacturers.

\section{Diagnosis of GHD in childhood}

The diagnosis of GHD in childhood is a multifaceted process requiring comprehensive clinical and auxological assessment, combined with biochemical tests of the GH-IGF axis and radiological evaluation. In a child with slow growth, whose history and auxology suggest GHD, normal GH response to provocative tests does not definitely rule out GHD. Some patients with auxology suggestive of GHD have IGF1 and/or IGF-binding protein-3 levels below the normal range but normal $\mathrm{GH}$ response to provocative tests. These children are not classically GH deficient but often have low spontaneous $\mathrm{GH}$ secretion over $24 \mathrm{~h}$, likely reflecting GH neurosecretory dysfunction. On the other hand, it remains that in suspected GHD, impaired GH responses to provocative tests will show GHD. Among classical provocative tests ITT, ARG and glucagon have been demonstrated the most reliable. Despite low peak GH response being arbitrarily defined as below 7 or $10 \mu \mathrm{g} / \mathrm{l}$, the third centile limits of normal response to these tests is markedly lower. The classical provocative tests stimulate $\mathrm{GH}$ secretion via actions at the hypothalamic level, but their within-subject reproducibility is very poor and implies their low Sp; this evidence recommended that GHD is demonstrated by failure to respond to two stimuli in order to reduce the numbers of false-positive GHD diagnosis. In combination with substances that inhibit or counteract somatostatin, e.g. ARG, pyridostigmine or GHS (25), GHRH becomes the most potent and reproducible stimulus of GH secretion; it explores the maximal secretory capacity of somatotroph cells that, in turn, reflects the appropriately normal function of hypothalamic network controlling $\mathrm{GH}$ synthesis and release. Provided that the peak GH response to these tests is referred to appropriate cut-off limits $(<20 \mu \mathrm{g} / \mathrm{l}$ in childhood), they are as reliable as classical provocative tests to distinguish between normal and deficient GH secretory capacity. They can be used as a single test (26).

\section{Diagnosis of GHD in the transition period adolescent-to-young adult}

The management of the GH-treated adolescent in the transition to adult care was first defined by the consensus guidelines produced by the European Society for Paediatric Endocrinology (ESPE) in collaboration with the GRS (27).

Transition was defined as a broad set of physical and psychosocial changes, arbitrarily defined as starting in late puberty and ending with full adult maturation. This usually implies a period from mid- to late teens until 6-7 years after achievement of final height. The aims of management in the transition period for the GH-treated adolescent obviously focused on diagnostic aspects in this peculiar phase of life.

In fact, GH and IGF1 secretion peaks at mid- to late puberty and subsequently declines. The GH replacement strategy differs in childhood from that adopted in adult life: in childhood, all degrees of GHD are considered for replacement, whereas in adult life only patients with severe GHD are presently treated. Thus, the re-evaluation of the diagnosis when the major paediatric goals of treatment have been reached is mandatory. In adolescents with GHD, treatment should therefore be stopped for re-evaluation of the diagnosis when growth and pubertal development are considered to be completed. The re-evaluation of pituitary function during transition is generally needed but can well be skipped in patients with severe congenital GHD or acquired panhypopituitarism.

The ESPE/GRS Consensus (27) stated that GH reserve is assessed by measurement of a serum IGF1 concentration and/or a GH stimulation test. The ITT was the recommended test with the ARG or glucagon tests as alternatives.

It was also recommended that the extent of GH-IGF1 re-evaluation depends on the a priori likelihood of profound GHD. Two groups of patients were distinguished:

i) high likelihood: those with severe GHD in childhood with or without two or three additional hormone deficits, which may be due to a defined genetic cause, and those with severe GHD due to structural hypothalamic-pituitary abnormalities, 
central nervous system (CNS) tumours or patients having received high-dose cranial irradiation, and

ii) low likelihood: the remaining patients, including those with idiopathic GHD, either isolated or with one additional hormone deficit.

In patients with a high likelihood of persistent GHD, an IGF1 value $<-2$ s.D. off GH treatment for at least 4 weeks should be considered sufficient evidence of profound GHD. If the IGF1 is $>-2$ s.D., a GH provocative test should be performed. If this shows a low $\mathrm{GH}$ response, the diagnosis of GHD is reconfirmed. If the peak $\mathrm{GH}$ is above the appropriate cut-off value, the diagnosis should be reconsidered.

Patients with lower likelihood of persistent GHD at retesting should have an IGF1 measurement and one GH provocation test. If both are low, the diagnosis of GHD is reconfirmed. If both are normal, the patient can be discharged unless he/she is at risk of evolving endocrinopathy, such as those who received prior CNS irradiation. If the tests are discordant, the patient should be followed up.

Regarding the cut-off level, it was considered that peak $\mathrm{GH}$ response $<3 \mu \mathrm{g} / \mathrm{l}$ after ITT assumed in adulthood would be too conservative in the transition period. As in normal children, the most exuberant $\mathrm{GH}$ response to a stimulation test occurs in late puberty, the ESPE/GRS Consensus proposed the cut-off for severe GHD in the transition period to be $<5 \mu \mathrm{g} / \mathrm{l}$. Also, it was recommended that any patient with severe GHD should have cranial and pituitary magnetic resonance imaging (MRI).

These diagnostic algorithm and recommendations still look well based, and have been of reference also in the more recent statements from the GRS Consensus 2007 (2).

First of all, it has to be emphasized that the ESPE/GRS guidelines provided some definite diagnostic value to the measurement of total IGF1 levels, in agreement with what has been proposed for adults $(2,4,27)$.
On the other hand, more recent studies provided evidence indicating the need to revise some statements of the ESPE/GRS about provocative tests and their appropriate cut-off limits for the diagnosis in patients at either high or low likelihood who have non-diagnostic IGF1 levels.

It is fully acceptable that, as in the adult, the ITT is a provocative test of reference $(2,4)$.

The cut-off level of $5 \mu \mathrm{g} / \mathrm{l}$ below which severe GHD is diagnosed in the transition adolescent was, however, an arbitrary assumption reflecting the lack of data. More recently, normative values for the ITT in the transition adolescents have been defined (28). In fact, the diagnostic accuracy of a peak GH response of $6.1 \mu \mathrm{g} / \mathrm{l}$ showed $96 \%$ Se with $100 \%$ Sp (Fig. 1). Based on these findings, it is clear that also the cut-off of $5 \mu \mathrm{g} / \mathrm{l}$ for ITT is too restrictive in the transition period, and this aspect has been recognized in the GRS Consensus 2007 (2).

Normative data for the $\mathrm{GH}$ response to glucagon and ARG alone have not been defined yet in the transition adolescent. On the other hand, the appropriate diagnostic cut-off limits for testing the GH response to GHRH+ARG in the transition period have been defined very recently (29). For this maximal provocative test, the best pair of the highest Se $(100 \%)$ and Sp (97\%) was found choosing a peak GH of $19.0 \mu \mathrm{g} / \mathrm{l}$ (Fig. 1). Thus, it should now be recognized that in late adolescent and early adulthood patients, a GH cut-off limit using the GHRH + ARG test lower than $19.0 \mu \mathrm{g} / \mathrm{l}$ is able to distinguish between GHD and normal subjects. Interestingly, as anticipated by previous studies (29), the GH response to this test does not substantially vary from infancy to early adulthood.

Thus, although the test of choice for the diagnosis of GHD during this period of life is considered ITT, it has to be taken into account that this test suffers from poor reproducibility and may be contraindicated in some clinical conditions, particularly after neurosurgery (30-33).
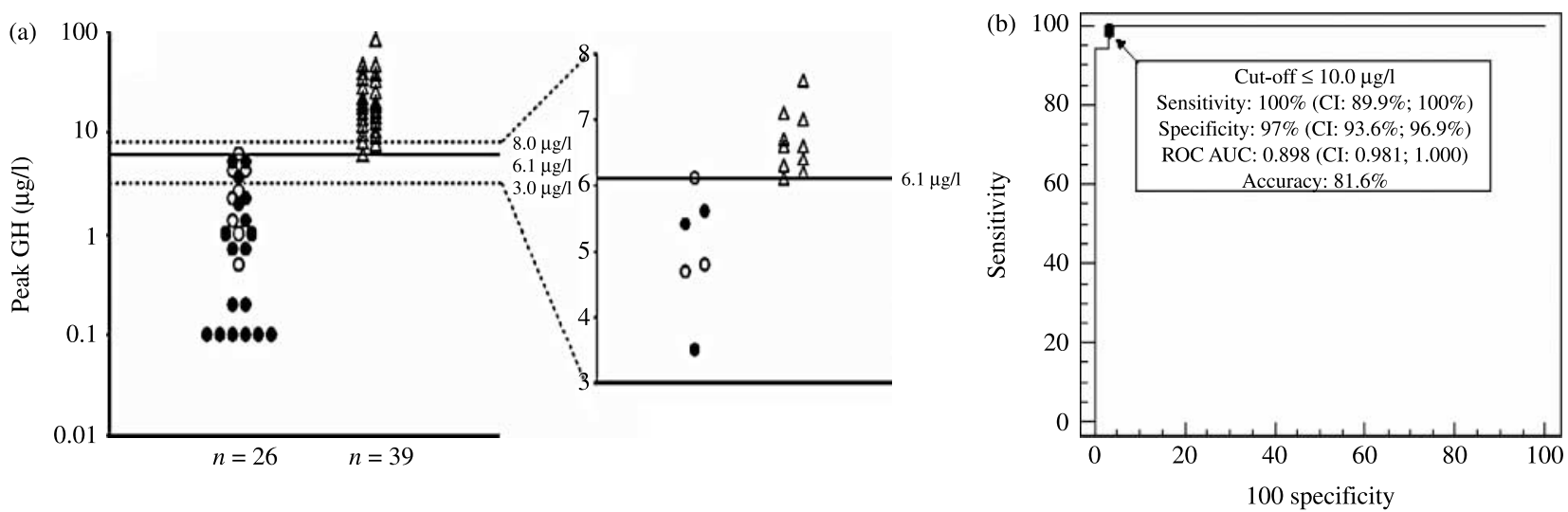

Figure 1 (a) Results of ITT in 26 subjects with isolated GH deficiency $(O)$ or multiple pituitary hormone deficiency $(\bullet)$ and in 39 age- and sex-matched controls $(\triangle) ; n$, number of subjects. Note logarithmic scale for peak GH in left graph and linear scale for GH cut-off between 3 and $8 \mu \mathrm{g} / \mathrm{l}$ in right graph. (b) ROC curve for peak serum GH responses to the GHRH + ARG test in lean adolescent and young adult population. The arrow indicates the location on the ROC curve of the diagnostic cut-off point that minimizes misclassification of panhypopituitary patients and control subjects. The cut-off point, sensitivity and specificity, with their confidence intervals $(\mathrm{Cl})$ at $95 \%, \mathrm{ROC}$ AUC and accuracy are shown in the box (adapted from (28) and (29) with the permission of the European Journal of Endocrinology). 


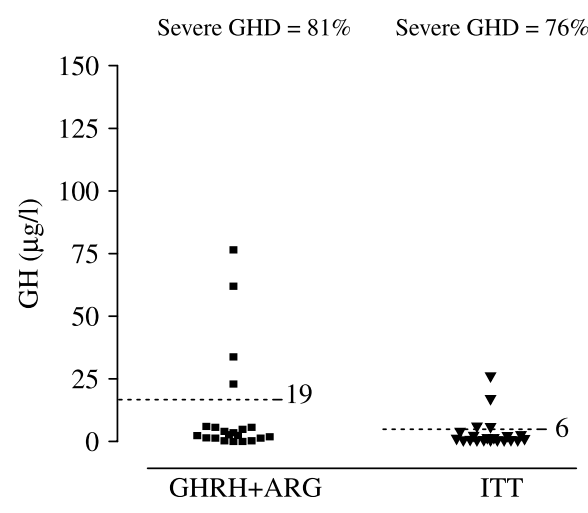

As GHRH + ARG test shows excellent Se and Sp in the adolescent as well as in adults, displays very good intraindividual reproducibility and has now definite normative levels in every phase of life, it can be considered an alternative test as reliable as ITT for retesting the transition adolescent (Fig. 2) (4, 29). Like in adulthood, since the combined tests stimulate both the hypothalamus and the pituitary, GHD due to hypothalamic disease (such as after cranial irradiation) may be missed $(2,4)$. Again, if the peak GH level during a GHRH + ARG test is normal in patients who had cranial irradiation, then an ITT should also be performed.

Again, it has to be considered that the cut-off limits for provocative tests (either GHRH + ARG or ITT) in the transition adolescent have been defined in lean subjects only; as anticipated, it would be preferable that these tests are validated also as a function of overweight and obesity $(2,4,29)$.

\section{Retesting the CO GHD: clinical aspects predicting persistence of severe GHD to be replaced}

Studies in literature reporting the results about retesting patients who had been treated with rhGH in childhood
Severe GHD $=35 \%$

Figure 2 Individual peak $\mathrm{GH}$ responses to both GHRH+ARG and ITT tests in patients with a paediatric diagnosis of organic multiple hypopituitarism $(n=21)$ (left panel) and in patients with a paediatric diagnosis of isolated GHD $(n=47)$ (right panel). Dotted lines represent limits of normal $\mathrm{GH}$ response to $\mathrm{GHRH}+\mathrm{ARG}$ and ITT in the transition phase $(28,29)$.

have found very different percentages of persistent severe GHD in adulthood, ranging from 12.5 to $90 \%$ (33-37). These studies have generally been performed in different cohorts of GHD patients with classical provocative tests that are known for their poor reproducibility (30-32, 38-40). This evidence clearly led to the statement that there is no justification for the view that patients diagnosed in childhood to be GHD should continue on therapy into adult life without their GH status being reinvestigated and shown to be persistently abnormal.

The inability to confirm GHD in adulthood could reflect transient GHD in childhood (34) or, alternatively, could merely reflect the lack of reproducibility of classical provocative tests (30-32, 38-40). It also has to be considered that even patients with normal $\mathrm{GH}$ response to provocative tests but showing impairment of spontaneous $\mathrm{GH}$ secretion are presently considered as GH insufficient (the so-called GH neurosecretory dysfunction) and treated with rhGH for replacement (41). In fact, by retesting the $\mathrm{GH}$ response to single GHRH + ARG test in a large cohort of patients who had undergone GH replacement in childhood, severe GHD in adulthood was generally confirmed in organic GHD (94\%), frequent in idiopathic GHD (52.1\%) but never occurred in $\mathrm{GH}$ neurosecretory dysfunction (37) (Fig. 3).
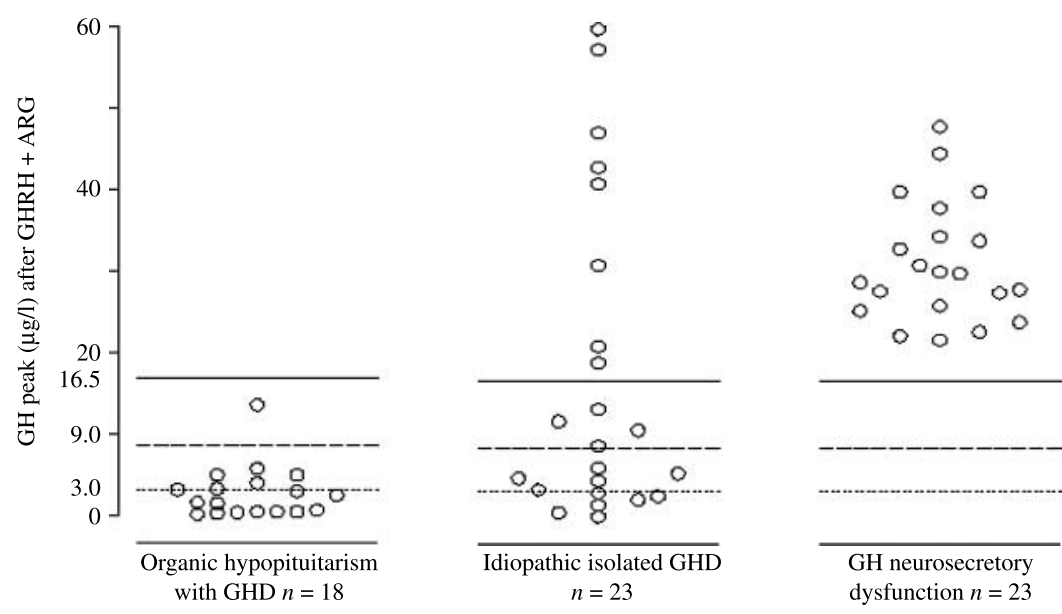

Figure 3 Individual $\mathrm{GH}$ peak after $\mathrm{GHRH}+$ ARG test in subjects who had been treated with $\mathrm{GH}$ in childhood as having organic (defined as $\mathrm{GH}$ peak $<10 \mu \mathrm{g} / \mathrm{l}$ after two classical tests and organic lesion on MRI) (left) or idiopathic (defined as GH peak $<10 \mu \mathrm{g} / \mathrm{l}$ after two classical tests but without organic lesion on MRI) (middle) or GH neurosecretory dysfunction (defined as $\mathrm{GH}$ peak $>10 \mu \mathrm{g} / \mathrm{l}$ after two classical tests but mean $\mathrm{GH}$ concentration over $24 \mathrm{~h}<3 \mu \mathrm{g} / \mathrm{l})$ (right). Lines are represented as follows: $(-)$ third and (- ) first centile limits of normal $\mathrm{GH}$ response to $\mathrm{GHRH}+\mathrm{ARG}$ and (...) the limit below which severe GHD is demonstrated by ITT in adults (adapted from (37) with the permission of The Journal of Clinical Endocrinology and Metabolism). 
The relationship between pituitary MRI features and persistence of CO-GHD in adult life has also been studied, showing that structural hypothalamic-pituitary abnormalities are determinant parameters in the prediction of the persistence of GHD. MRI findings of the hypothalamic-pituitary area in patients with GHD may be the most important criterion upon which the decision to re-evaluate the patient should be based. It has been shown that patients with GHD and congenital hypothalamic-pituitary abnormalities might not require re-evaluation of $\mathrm{GH}$ secretion, whereas patients with isolated GHD and a normal or small pituitary gland should be retested (33). In a recent study, it was demonstrated that a subgroup of subjects with $\mathrm{CO}$ idiopathic GHD presenting with congenital structural hypothalamic-pituitary abnormalities (defined as those with a $\mathrm{GH}$ response $<5 \mu \mathrm{g} / \mathrm{l}$ and with anterior pituitary hypoplasia, pituitary stalk agenesis and posterior pituitary ectopia at the level of the median eminence) are clearly candidates for permanent GHD in adult life (42), while those with less severe MRI features have an uncertain diagnosis or a likelihood of normal GH response after stimulation tests.

\section{Conclusions}

Retesting the diagnosis of severe GHD in adolescents who received treatment with rhGH in childhood is a hot topic in either paediatric or adult endocrinology.

Based on the data available so far, it can be concluded that:

i) $\mathrm{GH}$ retesting is not required for those with a transcription factor mutation (e.g. POU1F1, PROP1, HESX1, LHX3 and LHX4), those with more than three pituitary hormone deficits and those with isolated GHD associated with an identified mutation (e.g. GH, GHRHR, SOX3). All other patients should undergo retesting after at least 1 month of rhGH treatment.

ii) Very low IGF1 levels in patients highly suspected for GHD (i.e. congenital GHD or acquired multiple pituitary hormone deficits) can be definite evidence of persistent, severe GHD; these patients can skip provocative tests. However, it must be emphasized that normal IGF1 levels do not rule out severe GHD; patients suspected for GHD but displaying normal IGF1 levels must be investigated by provocative tests.

iii) The ITT is a test of reference and the cut-off level for this test in the transition adolescence is $\leq 6.0 \mu \mathrm{g} / \mathrm{l}$. However, other tests are as reliable as ITT. At present, the only alternative test that has been validated for retesting the transition adolescence is GHRH + ARG with a cut-off limit defined as $19.0 \mu \mathrm{g} / \mathrm{l}$. Neither ITT or GHRH + ARG cut-off limits in adolescents have been defined by BMI; given the confounding effect of overweight or obesity on the interpretation of the GH response to provocative tests, this validation is required in the near future.

iv) Among patients who had undergone rhGH treatment in childhood, severe GHD is generally confirmed by retesting in organic GHD, is frequent in idiopathic GHD, but never occurs in patients who had been treated for the so-called GH neurosecretory dysfunction.

\section{Funding}

This study was supported by a grant from the University of Turin and Fondazione per lo Studio delle Malattie Endocrino-Metaboliche, Turin, Italy.

\section{Disclosure}

This paper forms part of a European Journal of Endocrinology supplement, supported by Ferring Pharmaceuticals. The authors disclose: no potential conflicting relationship with Ferring. This article was subject to rigorous peer review before acceptance and publication.

\section{References}

1 Growth Hormone Research Society. Consensus guidelines for the diagnosis and treatment of adults with growth hormone deficiency: summary statement of the Growth Hormone Research Society Workshop on adult growth hormone deficiency. Journal of Clinical Endocrinology and Metabolism 199883 379-381.

2 Ho KK \& GH Deficiency Consensus Workshop Participants, . Consensus guidelines for the diagnosis and treatment of adults with GH deficiency II: a statement of the GH Research Society in association with the European Society for Pediatric Endocrinology, Lawson Wilkins Society, European Society of Endocrinology, Japan Endocrine Society, and Endocrine Society of Australia. European Journal of Endocrinology 2007157 695-700.

3 Molitch ME, Clemmons DR, Malozowski S, Merriam GR, Shalet SM, Vance ML, Endocrine Society's Clinical Guidelines Subcommittee \& Stephens PA. Evaluation and treatment of adult growth hormone deficiency: an Endocrine Society Clinical Practice Guideline. Journal of Clinical Endocrinology and Metabolism 200691 1621-1634.

4 Ghigo E, Aimaretti G \& Corneli G. Diagnosis of adult GH deficiency. Growth Hormone and IGF Research 200818 1-16.

5 Koranyi J, Svensson J, Götherström G, Sunnerhagen KS, Bengtsson B \& Johannsson G. Baseline characteristics and the effects of five years of $\mathrm{GH}$ replacement therapy in adults with $\mathrm{GH}$ deficiency of childhood or adulthood onset: a comparative, prospective study. Journal of Clinical Endocrinology and Metabolism $2001864693-4699$.

6 Attanasio AF, Lamberts SW, Matranga AM, Birkett MA, Bates PC, Valk NK, Hilsted J, Bengtsson BA \& Strasburger CJ. Adult growth hormone $(\mathrm{GH})$-deficient patients demonstrate heterogeneity between childhood onset and adult onset before and during human $\mathrm{GH}$ treatment. Adult Growth Hormone Deficiency Study Group. Journal of Clinical Endocrinology and Metabolism 1997 82 82-88.

7 Jorgensen JO, Pedersen SA, Thuesen L, Jorgensen J, IngemannHansen T, Skakkebaek NE \& Christiansen JS. Beneficial effects of growth hormone treatment in GH-deficient adults. Lancet 19891 1221-1225.

8 Kaufman JM, Taelman P, Vermeulen A \& Vandeweghe M. Bone mineral status in growth hormone-deficient males with isolated and multiple pituitary deficiencies of childhood onset. Journal of Clinical Endocrinology and Metabolism 19927 118-123. 
9 Aimaretti G, Corneli G, Razzore P, Bellone S, Baffoni C, Bellone J, Camanni F \& Ghigo E. Usefulness of IGF-I assay for the diagnosis of GH deficiency in adults. Journal of Endocrinological Investigation 199821 506-511.

10 Hartman ML, Crowe BJ, Biller BM, Ho KK, Clemmons DR, Chipman JJ, HyposCCS Advisory Board \& US HypoCCS Study Group. Which patients do not require a GH stimulation test for the diagnosis of adult GH deficiency? Journal of Clinical Endocrinology and Metabolism 200287 477-485.

11 Hilding A, Hall K, Wivall-Helleryd IL, Sääf M, Melin AL \& Thorén M. Serum levels of insulin-like growth factor I in 152 patients with growth hormone deficiency, aged 19-82 years, in relation to those in healthy subjects. Journal of Clinical Endocrinology and Metabolism 199984 2013-2019.

12 Granada ML, Murillo J, Lucas A, Salinas I, Llopis MA, Castells I, Foz M \& Sanmartí A. Diagnostic efficiency of serum IGF-I, IGFbinding protein-3 (IGFBP-3), IGF-I/IGFBP-3 molar ratio and urinary $\mathrm{GH}$ measurements in the diagnosis of adult GH deficiency: importance of an appropriate reference population. European Journal of Endocrinology 2000142 243-253.

13 Marzullo P, Di Somma C, Pratt KL, Khosravi J, Diamandis A, Lombardi G, Colao A \& Rosenfeld RG. Usefulness of different biochemical markers of the insulin-like growth factor (IGF) family in diagnosing growth hormone excess and deficiency in adults. Journal of Clinical Endocrinology and Metabolism $2001863001-3008$.

14 Boquete HR, Sobrado PG, Fideleff HL, Sequera AM, Giaccio AV, Suárez MG, Ruibal GF \& Miras M. Evaluation of diagnostic accuracy of insulin-like growth factor (IGF)-I and IGF-binding protein-3 in growth hormone-deficient children and adults using ROC plot analysis. Journal of Clinical Endocrinology and Metabolism $2003884702-4708$.

15 Aimaretti G, Corneli G, Baldelli R, Di Somma C, Gasco V, Durante C, Ausiello L, Rovere S, Grottoli S, Tamburrano G \& Ghigo E. Diagnostic reliability of a single IGF-I measurement in 237 adults with total anterior hypopituitarism and severe GH deficiency. Clinical Endocrinology 200359 56-61.

16 Gómez JM, Espadero RM, Escobar-Jiménez F, Hawkins F, Picó A, Herrera-Pombo JL, Vilardell E, Durán A, Mesa J, Faure E \& Sanmartí A. Growth hormone release after glucagon as a reliable test of growth hormone assessment in adults. Clinical Endocrinology 200256 329-334.

17 Conceicao FL, da Costa e Silva A, Leal Costa AJ \& Vaisman M. Glucagon stimulation test for the diagnosis of GH deficiency in adults. Journal of Endocrinological Investigation 200326 1065-1070.

18 Biller BM, Samuels MH, Zagar A, Cook DM, Arafah BM, Bonert V, Stavrou S, Kleinberg DL, Chipman JJ \& Hartman ML. Sensitivity and specificity of six tests for the diagnosis of adult GH deficiency. Journal of Clinical Endocrinology and Metabolism 200287 2067-2079.

19 Aimaretti G, Corneli G, Razzore P, Bellone S, Baffoni C, Arvat E, Camanni F \& Ghigo E. Comparison between insulin-induced hypoglycemia and growth hormone (GH)-releasing hormone + arginine as provocative tests for the diagnosis of $\mathrm{GH}$ deficiency in adults. Journal of Clinical Endocrinology and Metabolism $1998 \mathbf{8 3}$ 1615-1618.

20 Darzy KH, Aimaretti G, Wieringa G, Gattamaneni HR, Ghigo E \& Shalet SM. The usefulness of the combined growth hormone (GH)releasing hormone and arginine stimulation test in the diagnosis of radiation-induced $\mathrm{GH}$ deficiency is dependent on the postirradiation time interval. Journal of Clinical Endocrinology and Metabolism $2003 \mathbf{8 8}$ 95-102.

21 Maccario M, Grottoli S, Procopio M, Oleandri SE, Rossetto R, Gauna C, Arvat E \& Ghigo E. The GH/IGF-I axis in obesity: influence of neuro-endocrine and metabolic factors. International Journal of Obesity and Related Metabolic Disorders 200024 S96-S99.

22 Corneli G, Di Somma C, Baldelli R, Rovere S, Gasco V, Croce CG, Grottoli S, Maccario M, Colao A, Lombardi G, Ghigo E, Camanni F \& Aimaretti G. The cut-off limits of the GH response to GH-releasing hormone-arginine test related to body mass index. European Journal of Endocrinology 2005153 257-264.
23 Popovic V, Leal A, Micic D, Koppeschaar HP, Torres E, Paramo C, Obradovic S, Dieguez C \& Casanueva FF. GH-releasing hormone and GH-releasing peptide- 6 for diagnostic testing in GH-deficient adults. Lancet 2000356 1137-1142.

24 Kelestimur F, Popovic V, Leal A, Van Dam PS, Torres E, Perez Mendez LF, Greenman Y, Koppeschaar HP, Dieguez C \& Casanueva FF. Effect of obesity and morbid obesity on the growth hormone (GH) secretion elicited by the combined GHRH + GHRP-6 test. Clinical Endocrinology $2006 \mathbf{6 4} 667-671$.

25 Fairhall KM, Mynett A \& Robinson IC. Central effects of growth hormone-releasing hexapeptide (GHRP-6) on growth hormone release are inhibited by central somatostatin action. Journal of Endocrinology $1995 \mathbf{1 4 4}$ 555-560.

26 Schneider HJ, Corneli G, Kreitschman-Andermahr I, Rovere S, Bellone S, Bona G, Ghigo E\& Aimaretti G. Traumatic brain injury and hypopituitarism in children and adolescents: is the problem underestimated? Pediatric Endocrinology Reviews 20074 205-209.

27 Clayton PE, Cuneo RC, Juul A, Monson JP, Shalet SM, Tauber M \& European Society of Paediatric Endocrinology. Consensus statement on the management of the GH-treated adolescent in the transition to adult care. European Journal of Endocrinology 2005 $152165-170$.

28 Maghnie M, Aimaretti G, Bellone S, Bona G, Bellone J, Baldelli R, de Sanctis C, Gargantini L, Gastaldi R, Ghizzoni L, Secco A, Tinelli C \& Ghigo E. Diagnosis of GH deficiency in the transition period: accuracy of insulin tolerance test and insulin-like growth factor-I measurement. European Journal of Endocrinology 2005152 589-596.

29 Corneli G, Di Somma C, Prodam F, Bellone J, Bellone S, Gasco V, Baldelli R, Rovere S, Schneider HJ, Gargantini L, Gastaldi R, Ghizzoni L, Valle D, Salerno M, Colao A, Bona G, Ghigo E, Maghnie M \& Aimaretti G. Cut-off limits of the GH response to GHRH plus arginine test and IGF-I levels for the diagnosis of GH deficiency in late adolescents and young adults. European Journal of Endocrinology 2007157 701-708.

30 Ghigo E, Bellone J, Aimaretti G, Bellone S, Loche S, Cappa M, Bartolotta E, Dammacco F \& Camanni F. Reliability of provocative tests to assess growth hormone secretory status. Study in 472 normally growing children. Journal of Clinical Endocrinology and Metabolism 199681 3323-3327.

31 Vestergaard P, Hoeck HC, Jakobsen PE \& Laurberg P. Reproducibility of growth hormone and cortisol responses to the insulin tolerance test and the short ACTH test in normal adults. Hormone and Metabolic Research 199729 106-110.

32 Hoeck HC, Vestergaard P, Jakobson PE \& Laurberg P. Test of growth hormone secretion in adults: poor reproducibility of the insulin tolerance test. European Journal of Endocrinology 1995133 305-312.

33 Maghnie M, Strigazzi C, Tinelli C, Autelli M, Cisternino M, Loche S \& Severi F. Growth hormone (GH) deficiency (GHD) of childhood onset: reassessment of $\mathrm{GH}$ status and evaluation of the predictive criteria for permanent GHD in young adults. Journal of Clinical Endocrinology and Metabolism $1999 \mathbf{8 4} 1324-1328$.

34 Toogood AA \& Shalet SM. Diagnosis of severe growth hormone (GH) deficiency in young adults who received GH replacement therapy during childhood. Acta Paediatrica 1997423 117-120.

35 Tauber M, Moulin P, Pienkowski C, Jouret B \& Rochiccioli P. Growth hormone $(\mathrm{GH})$ retesting and auxological data in 131 $\mathrm{GH}$-deficient patients after completion of treatment. Journal of Clinical Endocrinology and Metabolism 199782 352-356.

36 Attanasio AF, Howell S, Bates PC, Blum WF, Frewer P, Quigley C \& Shalet SM. Confirmation of severe GH deficiency after final height in patients diagnosed as GH deficient during childhood. Clinical Endocrinology 200256 503-507.

37 Aimaretti G, Baffoni C, Bellone S, Di Vito L, Corneli G, Arvat E, Benso L, Camanni F \& Ghigo E. Retesting young adults with childhood-onset growth hormone (GH) deficiency with GH-releasing-hormone-plus-arginine test. Journal of Clinical Endocrinology and Metabolism 200085 3693-3699.

38 Tassoni P, Cacciari E, Cau M, Colli C, Tosi M, Zucchini S, Cicognani A, Pirazzoli P, Salardi S \& Balsamo A. Variability of 
growth hormone response to pharmacological and sleep tests performed twice in short children. Journal of Clinical Endocrinology and Metabolism 199071 230-234.

39 Loche S, Cappa M, Ghigo E, Faedda A, Lampis A, Carta D \& Pintor C. Growth hormone response to oral clonidine test in normal and short children. Journal of Endocrinological Investigation 199316 899-902.

40 Carel JC, Tresca JP, Letrait M, Chaussain JL, Lebouc Y, Job JC \& Coste J. Growth hormone testing for the diagnosis of growth hormone deficiency in childhood: a population register-based study. Journal of Clinical Endocrinology and Metabolism 199782 2117-2121.

41 Growth Hormone Research Society. Consensus guidelines for the diagnosis and treatment of growth hormone $(\mathrm{GH})$ deficiency in childhood and adolescence: summary statement of the $\mathrm{GH}$ Research Society. GH Research Society. Journal of Clinical Endocrinology and Metabolism 200085 3990-3993.

42 Léger J, Danner S, Simon D, Garel C \& Czernichow P. Do all patients with childhood-onset growth hormone deficiency (GHD) and ectopic neurohypophysis have persistent GHD in adulthood? Journal of Clinical Endocrinology and Metabolism 200590 650-656.

Received 5 September 2008

Accepted 17 September 2008 